\title{
LIDERAZGO PARA LOS PROCESOS DE DESARROLLO: LA VARIABLE DE GÉNERO
}

Dra. Rosalía Arteaga Serrano*

\section{LOS PROCESOS HISTÓRICOS: INTRODUCCIÓN}

$\mathbf{P}$ odría empezar abordando este tema, sobre las condiciones que entraña el liderazgo y las características necesarias para un líder, como aquellas establecidas de formación, perseverancia, capacidad de mover a otros sobre la base de sus motivaciones e ideales o de otra parte, sintonizar de tal manera con los ideales, con las razones de un grupo, de una multitud, de un estado, de un pueblo, que se vuelve indispensable para conducirlos a aquello que quieren o creen que quieren.

También podría detenerme para hablar de los buenos y los malos liderazgos, de aquellos hombres y mujeres que usan su ascendiente por sobre una colectividad, para cometer delitos, para adueñarse de bienes que no les corresponden, en fin, hasta para la creación de grupos y pandillas delictivas. Podría referirme también a diferentes tipos de liderazgo como el religioso, el que ejercen los ministros de los diferentes cultos y hasta de las sectas, que tan propensas han sido en aparecer en las postrimerías del siglo XX 0 en los comienzos del XXI, de los liderazgos de diversa índole, que abarcan los deportivos, los económicos, los empresariales, en fin, toda una extensa gama en la que no vamos a entrar.

Decía el estudioso inglés Michael Korda en su libro "El Poder", que: "Toda la vida no es sino un juego para alcanzar el poder".

Probablemente si seguimos sus dictámenes, estaríamos convirtiéndonos en un Machiavelo moderno o tal vez en un Machiavelo con faldas, si hablamos del género como eje transversal y de la búsqueda de la igualdad de oportunidades para hombres y muje-

* Ex Ministra de Educación y Cultura del Ecuador, Ex Vicepresidenta Constitucional de la República del Ecuador, Alta Comisionada de la Red de Universidades Regionales de Latinoamérica (UREL). 
res para apuntar las bases de una ética, que hasta vaya más allá de la política, que lo englobe todo, como cuando Lenin exponía que el mundo se mueve fundamentalmente por dos razones: por sexo y por hambre. Y va más allá Michael Korda, cuando dice: "lo importante es conocer las reglas del juego de la sociedad en la que se vive y saber utilizarlas en beneficio propio". Esto sería como repetir en otros términos la posición aquella de que "el fin justifica los medios", aforismo o consejo con el que no estoy absolutamente de acuerdo, como lo demostré palpablemente en los acontecimientos en los que el Ecuador y yo nos vimos envueltos en febrero de 1997.

Podemos también preguntarnos qué tipo de liderazgo deseamos, si aquel que está destinado o se estructura para mantener los esquemas actuales o el que piensa realmente en el cambio, en la búsqueda de un futuro mejor.

Esto último puede parecer una verdad de Perogrullo o un idealismo bobalicón, depende de la óptica con que se lo mire, pero al menos vale la pena mencionarlo, detenernos por unos momentos a pensar en ello.

En "el líder del cambio", obra del escritor John P. Kotter, se hace un análisis de cuáles son los elementos fundamentales que los propician, cuáles son los componentes que integran las cualidades de quienes quieren asumir el papel de líderes en las actuales circunstancias del devenir humano, qué debemos hacer, cuáles son los errores que debemos evitar.

El mundo actual, este de la Tercera Ola, como nos lo advierte desde hace ya décadas el pensador Alvin Toffler o el surgido de la teoría del caos, en palabras de llia Prigoguin, es el mismo en que los seres humanos vivieron desde su aparición sobre la tierra, pero también tenemos que coincidir en que es extremadamente diferente. Las razones de la ciencia, la tecnología, la innovación, no nos dejan exagerar ni mentir y allí están los avances de las comunicaciones: los satélites, la cibernética, la informática, y ahora, más que nunca, la genética con toda su carga de descubrimientos que partiendo del ADN, se aventuran por el desciframiento del mapa de la genética humana y llegan a la clonación, primero de vegeta- 
les y animales, y ya no tiene más trabas que la ética, para hacerlo con los seres humanos. La genómica ya no es un patrimonio de la ciencia ficción, es una realidad que a veces aterra, pero que más bien como en mi caso, nos anima a pensar en las maravillosas posibilidades de mejorar la calidad de vida de los seres humanos.

Pues bien, si pensamos en líderes para el cambio, los que van a estar inmersos en esta cambiante, rica y hasta espeluznante realidad, tenemos que pensar en qué decirles a las nuevas generaciones, sin duda, ya protagonistas de este mundo, que van a requerir estar extraordinariamente bien dotados, para actuar con éxito. Ello impedirá el perderse en los vericuetos del exceso de información o en los cantos de sirena que nos dicen que los valores no cuentan o que todo vale o que la técnica, la ciencia hacen intrascendentes esos viejos principios del bien o del mal o hasta de aquellos contenidos en los ancestrales derechos naturales, de todos los pueblos, de todas las regiones, aquellos asimilables a los modernos derechos humanos, como el de la vida, el de la honra, el de la libertad, el de no hacer daño a los demás, y muchos otros que no es del caso mencionar.

\section{APARECIMIENTO DE NUEVOS FACTORES SOCIALES EN AMÉRICA LATINA: MUJERES, JÓVENES, INDÍGENAS. INVISI- BILIDAD DE ESTOS ACTORES Y CONCRETAMENTE DE LA MUJER}

La historia de nuestra América Latina es, ciertamente, reciente si la comparamos con la antigüedad de las culturas que poblaron otros continentes y de las que la historia lleva un registro más minucioso que en los casos americanos.

El descubrimiento y la conquista significaron una irrupción, que relegó a papeles absolutamente secundarios y por supuesto invisibles a los antiguos habitantes de estos territorios, que, salvo esporádicos levantamientos, pasan a tener un nivel de protagonismo a partir de la famosa celebración del Descubrimiento: encuentro entre dos mundos como lo calificaron los organismos internacionales, cargándole las tintas al tema del mestizaje que no debemos de 
ninguna manera minimizar. Si lo hacemos desconoceríamos nuestra propia presencia y aporte a lo que viene siendo nuestra historia republicana y nuestra impronta en el contexto internacional o los 500 años de resistencia como denominaron los pueblos indios a los actos conmemorativos.

De alguna manera, los ojos de muchos se focalizan otra vez sobre la temática y el accionar indígena, que alcanza cada vez más relevancia en América Latina y particularmente en países como el Ecuador, que ya cuenta con un porcentaje revelador de autoridades indígenas electas, sobre todo en la región interandina, y tiene presencia a través de organizaciones como la poderosa Confederación de Nacionalidades Indígenas del Ecuatorianas (CONAIE).

En otro aspecto, América Latina es un continente de jóvenes, y por ello lo es de la esperanza, con sus problemáticas particulares y comunes a otros sectores de la población, preocupados por el deterioro de los ecosistemas y el equilibrio del planeta, por las perspectivas laborales, ya que el trabajo se ha convertido en el principal tema económico, social y cultural del momento, sin dejar de lado consideraciones como identidad versus globalización, inseguridad etc.

Las predicciones de la ONU sobre el envejecimiento de la población europea y el crecimiento negativo, nos dicen que Europa necesitará unos 160 millones de inmigrantes en los próximos 25 años para garantizar su supervivencia económica, con lo que el futuro de los jóvenes latinoamericanos podría ser ir a engrosar los grupos de trabajadores del viejo continente, no siempre en las mejores condiciones. Sin embargo, es verdad que en países como los nuestros, el componente juvenil es extremadamente importante inclusive para temas como el enfoque de las campañas electorales, para la captación de votantes o el resultado de los anuncios publicitarios que tienen un target nada despreciable en los grupos etáreos de adolescentes y jóvenes. Su invisibilidad ya no puede ser tal.

Es al tema de la mujer, al que vamos a prestarle un particular interés porque no puede ser soslayado en los actuales momentos si hacemos caso, por ejemplo, al premio Nóbel de Literatura, Gabriel García Márquez, quien decía que la auténtica revolución de estos 
tiempos es la participación de la mujer. O si no dejamos pasar por alto las viejas predicciones y las lecturas astrales que nos hablan del ingreso a la era de acuario, era que tiene como signo a la mujer.

No pretendo hacer de este, un discurso feminista, nunca me he considerado una, pero sí llamar la atención, focalizar la mente en los discrímenes que los siglos consagraron, en las luchas y los aportes que la mujer da y puede dar a la humanidad, sobre todo a partir de su irrupción en el ámbito público, así como en la confusión, las polémicas y los cambios que ha traído aparejados.

\section{VISIÓN GLOBAL}

En el transcurso de unas contadas generaciones, la mujer se halló ante un nuevo mundo de posibilidades, pero también de dificultades y obstáculos, que, generalmente, no estaba preparada para resolver. Tenía que abrirse un camino en sociedades en las que todo favorecía al hombre, desde las tradiciones, los conocimientos atávicos, las oportunidades laborales, sus propias limitaciones y hasta complejos inculcados en su mente por una educación alienante.

Kathleen Newland, en el ensayo la mujer y la política, nos dice esta dura verdad: "los casos de mujeres que ejercieron el poder político por derecho propio son tan poco comunes a lo largo de la historia que han adquirido sabor de leyenda. Pensemos en ellas, Isabel I, Juana de Arco, Cleopatra, Catalina la Grande... Los héroes pasan a la posteridad en estatuas ecuestres, las mujeres más a menudo lo hacen como Santas o Parias".

Lo anteriormente anotado no deja de ser una incontrovertible verdad, casi hasta nuestros días. Hay mujeres que llegaron a ser poderosas gracias a su calidad de esposas o amantes de hombres también poderosos (la historia registra incontables nombres), pero recordemos que les estaba vedado alcanzar el poder por vías convencionales.

Vale la pena refrescar nuestra memoria con algunos acontecimientos y fechas importantes en la lucha por alcanzar derechos civiles y políticos por parte de las mujeres: 
1893: Nueva Zelanda otorga por primera vez el voto a la mujer. 1929: Ecuador fue el primer país en América Latina, que concedió el sufragio a la mujer.

Aunque estas "concesiones" no garantizaban la "independencia de criterio" supeditado a los varones de la casa.

La misma Kathleen Newland nos dice: "la mujer que por excepción llega a ocupar un alto cargo, adquiere notoriedad por ese solo hecho; se hace más conspicua por la tendencia a exhibir su caso como un ejemplo de la participación de la mujer en el gobierno, cuando no para distraer la atención hacia la poca intervención que en los asuntos públicos le cabe a la mujer en general". Podemos coincidir en que esta apreciación sigue siendo válida en buena parte de países, pero no en todos. Hay algunos en los que se ha hecho más frecuente esta participación, aunque persiste la enorme responsabilidad que pesa sobre la mujer que ocupa un cargo público relevante, porque su fracaso, puede ser interpretado, no como un fallo personal sino del género al que representa. Aún nos quedan muchas barreras que derribar y están, más que en el ámbito legal, en donde se han conseguido ya notables avances, en el campo del ejercicio de los derechos y en la superación de trabas psicológicas y de tradición.

Y esto que decimos vale para cualquier tipo de sociedad: está claro que en algunas culturas orientales, en religiones como la musulmana, las barreras vienen teñidas por un tinte de religiosidad, que no se dan por ahora en el mundo occidental.

Según Mao Tse Tung, antes de la revolución, el chino llevaba sobre sus espaldas tres montañas: el feudalismo, el capitalismo y la superstición, pero la mujer china llevaba cuatro: los tres citados y un hombre. Sékou Touré, de Guinea, expresó algo parecido cuando dijo que las mujeres de su país habían sido "esclavas de esclavos".

Dentro del ejercicio de la política, tanto al interior de los partidos políticos como en el desempeño de la labor pública, la función característica de la mujer es prestar apoyo a la política que hacen los varones, con aquellas excepciones que sirven para confirmar la regla. 
Así nos explicamos el que, como todo grupo que actúa "desde fuera", la mujer debe empeñarse más que el hombre para obtener el mismo resultado, en palabras de la política estadounidense Jean Kirkpatrick, ya que "La mujer que busca sobresalir debe trabajar siempre un poco más, ser un poco más meticulosa, tener mejor asistencia y saber mucho más, si espera vencer la desconfianza de sus colegas y lograr su aprobación".

El impedimento más serio que encuentra la mujer en su camino continúa siendo siempre, sin ninguna duda, la persistencia de la idea, compartida por hombres y mujeres, de que la política y los asuntos públicos son por naturaleza, del exclusivo dominio del hombre. Esta tradición tiene raíces muy profundas en el pasado. Claro que hay quienes argumentan que lo que empujó al hombre a dedicarse a estas actividades fue su profundo sentido de inferioridad a causa de la imposibilidad de tener hijos. ¿Ustedes que opinan?

En todo caso, la primera y fundamental división del trabajo en la especie humana fue: espacio público - hombre, espacio privado mujer.

Hay otros obstáculos que la mujer tiene que vencer en su camino hacia el ejercicio de la política y del liderazgo en sus respectivas sociedades, obstáculos que también los tiene el hombre, pero en menor medida, debido a la ancestral estructura social.

Así, el alfabetismo es definitivamente uno de los registros más importantes para cualquier clase de participación política. En tiempos de la revolución Rusa Lenin afirmó que: "una persona que no sabe leer ni escribir queda fuera de la política, primero debe aprender el alfabeto y solo entonces la política será tal y no solamente rumores, chismes, cuentos de hadas y prejuicios".

En cualquier punto geográfico que se analice cuestiones de alfabetismo se verá que del total de personas que no saben leer ni escribir, el número de mujeres sobrepasa al de hombres.

La educación abre las puertas al conocimiento y a la confianza en sí mismo, dos componentes esenciales de la libre determinación, 
ya que el sistema educativo es la única institución que puede atacar las bases de la desigualdad sexual. Debemos decir además que buena parte del aparato educativo formal está en manos femeninas, empezando por los porcentajes de maestras de la educación básica, que en muchos países superan ya el $90 \%$ y en la educación media y hasta universitaria.

Germainne Greer en "The Female Eunuch" dice: "si las mujeres se dieran cuenta de su valor potencial como seres independientes e insistieran en aplicar sus talentos a la vida de relación -política, negocios y tecnología, además de la vida familiar- la civilización podría llegar a la madurez y no a la aniquilación.

Existen barreras internas que deben ser superadas, pero también es necesario reconocer, entre otras cosas, algo que ya se ha vuelto un lugar común el mencionarlo, pero en lo que es necesario ser reiterativa, y es la doble y hasta la triple carga que soporta la mujer que trabaja, aún en la más evolucionada de las sociedades. Triple, cuando se trata de mujeres creadoras e investigadoras y cuando hacemos referencia al famoso ocio creativo al que pocas mujeres tenemos acceso.

También debe mencionarse, el hecho de que hasta hace muy poco tiempo debíamos lamentar la ausencia de modelos femeninos de actuación relevante en las escalas superiores de la vida académica, así como en los otros estadios del quehacer humano, lo que se suma a la existencia de un código no escrito de conducta, que también perjudica a la mujer.

Podemos concluir que, a pesar de todas las limitaciones, la educación da a las mujeres "entrada al sistema". Una vez allí, ellas tendrán que demostrar cuánto valen.

Patricia Mcgrath se plantea que: si, lo más probable es que al mejorar uno de los sexos, ambos se beneficien. Sin embargo, un gran cambio en la vida de la mujeres incide necesariamente sobre los hombres y los niños quienes se ven obligados a realizar ciertos ajustes compensatorios.

¿Acaso el hecho de que haya más doctoras y ejecutivas significará inevitablemente que deban haber más enfermos y secretarios? 
Tenemos que evitar el "apartheid" de los sexos en este mundo que tiende a reconocer las diferencias, las diversidades, pero que debe tender también a aceptarlas y a disfrutarlas

\section{LA PRESENCIA DE LA MUJER EN LOS PROCESOS DEMOCRÁ- TICOS. APORTES: HONESTIDAD, TRANSPARENCIA, EQUIDAD, SIMULTANEIDAD}

Blithz Lozada, filósofo boliviano, cita a Foucault en su libro: "Foucault, feminismo, filosofía..." cuando dice que "Foucault establece que las distinciones entre los sexos son el resultado de las relaciones y las redes de poder sustentadas por un determinado saber triunfante" y reconoce que: "la genealogía política de Foucault sirvió al feminismo para resaltar las relaciones entre los sexos sustantivando un intercambio particularmente denso, como relaciones concretas de poder".

Las definiciones de democracia nos remontan a los vocablos griegos y dentro de ella, a la democracia ateniense que fue la más representativa, en la que sin embargo la mujer no tenía cabida. Allí no se hablaba de los derechos y de las igualdades entre los sexos, ni siquiera se habría planteado aquella bella frase de Susan Sontag traída también por Blithz Lozada: "Lo más hermoso que existe en los hombres viriles es algo femenino; lo más hermoso que existe en las mujeres femeninas, es algo masculino".

Pese a todas las críticas que se le puede hacer a la democracia como sistema de gobierno y de vida, es el más perfectible de todos los sistemas y dentro de él nos toca a las mujeres y a los hombres desenvolvernos tratando de alcanzar la plenitud.

Ambos sexos participan de una cultura institucional que refuerza los estereotipos, sin que en los currículos explícitos e implícitos se "incorporen los aportes de las mujeres a la ciencia, la cultura, la política y el desarrollo económico, su participación a lo largo de la historia, la variedad de trabajos que desempeñan, su papel en las organizaciones comunitarias, en la defensa de los derechos humanos, la salud y el medio ambiente" (Gloria Bonder). Como tampoco, añadiríamos, en la consecución y consolidación de la democracia. 
Si bien asistimos, gracias a los avances legales, a una igualdad formal, estamos inmersos todavía en una desigualdad real. En el caso ecuatoriano, Julio César Trujillo establece que "el reconocimiento jurídico es quizá el que menos resistencia ha encontrado en la sociedad ecuatoriana, no así el tránsito de este reconocimiento formal al sociológico, es decir, la vigencia de esos derechos en la vida cotidiana o en la práctica de la vida social". Esto, a pesar de Ecuador, por ejemplo, lo común ha sido y es que se reconozca la jefatura femenina, pero solamente ante la ausencia del cónyuge o de un varón adulto en el hogar.

Hay, en nuestras democracias, una contradicción entre subordinación sexual y construcción democrática, la naturaleza del poder, la polaridad esfera pública-esfera privada y en la cotidianidad como un hecho político.

Históricamente, como hemos visto, lo público se ha definido como contrapuesto a lo privado: lo público pertenece a los hombres, lo privado a las mujeres y a lo sumo, lo afirmable sería que las mujeres participan -y han participado- en lo público desde una cultura política propia y con métodos, en algunos casos, diferentes de los masculinos.

Los actuales procesos de globalización económica y de las comunicaciones, hacen girar ahora los retos nacionales en la capacidad que acertar en las formas de inserción en la economía mundial, elevar la productividad y la competitividad y lograr mayores niveles de equidad interna.

Para ello los liderazgos femeninos que empiezan por desarrollarse en los propios hogares, nos dicen, sobre todo en poblaciones de altos porcentajes migratorios, de su participación como jefas de hogar, trabajadoras remuneradas fuera de su casa, su inserción en la formación y promoción gerencial y en el manejo de nuevas tecnologías, por lo que, los gobiernos deberían garantizar su acceso a la transferencia tecnológica y al asesoramiento y cooperación internacionales.

Hay circunstancias que nos son atribuibles a las mismas mujeres. Maruja Barrig dice: "una de las debilidades del movimiento de mujeres/ feminista, es la poca capacidad que hemos demostrado en 
hacer análisis más globales sobre la política y lo político... La dignidad pasa por el reconocimiento de nuestros derechos como "ciudadanas" y no de "necesitadas". Y concluye: "lo que no es bueno para la democracia no es bueno para las mujeres" con lo que deja establecido un interesante binomio: democracia - mujer.

En los diferentes países de América Latina, la ley de cuotas, basada en una discriminación positiva ha permitido un mayor ingreso de las mujeres a la lid política y a integrarse como miembros sobre todo a organismos colegiados; concejos municipales, cámaras congresiles, etc.

La evolución que se da en los últimos tiempos puede atribuirse a tres aspectos fundamentales que la explican:

1 La creación del dispositivo de participación.

${ }_{1}$ El interés que han tenido las mujeres en participar y

1 El interés de muchos sectores de la sociedad civil, por apoyar candidaturas femeninas.

No todo es fácil: en los procesos electorales, la contracampaña para las mujeres se ampara en la honorabilidad" de la mujer y en "la maternidad". A las mujeres líderes se las tiende a encasillar como "madres sacrificadas y abnegadas" o como "amantes de alguna autoridad" y por esos dos mecanismos se trata de descalificarlas, sobre todo si aparecen con reales opciones de triunfo.

En el caso de candidaturas femeninas se plantea también una discusión sobre el tema, traído por Arturo Granados, de "si las mujeres piensan en las mujeres solamente o si piensan en el conjunto de los problemas nacionales". El desafío consiste en que las candidaturas femeninas deberán hacer el doble esfuerzo.

Hace algunos años, una mujer campesina del centro de la Sierra del Ecuador, al término de un curso de capacitación, daba su testimonio de vida y decía: " Las mujeres, antes, no han sabido participar. Antes, solo han sido puro hombres. Entraban al Cabildo solo hombres, pero las mujeres tenían que estar solo en la casa..." Al ex- 
presar esas palabras, esta mujer demostraba su admiración al descubrir ese mundo de segregación y discrimen doloroso, existente no solo en el campo sino en toda la geografía de esta América Latina.

Aurora Iza, que así se llamaba esta mujer, expresaba con inocencia un evidente testimonio de la lucha ancestral de las mujeres por alcanzar el reconocimiento de la igualdad de sus derechos. Y digo ancestral, porque uno de los discrímenes siempre presente en la historia de la humanidad es, precisamente, el que ha afectado a la mujer.

A medida que pasamos las páginas de la historia de América Latina e incluso, la del mundo, vienen a nuestra mente una serie de interrogantes sin respuestas satisfactorias. ¿Por qué la memoria colectiva solo recoge los hechos de los hombres y no los de las mujeres? ¿Por qué la presencia de figuras femeninas en algunos campos de la vida humana es tan reducida, casi inexistente? ¿Por qué no constan, permanentemente, nombres de mujeres en las listas de autoridades y liderazgos políticos? ¿Por qué, el papel de las mujeres en la historia, está reducido a lo que los alemanes llaman las 3 "K" Kuchen, Kinder y Kunst, es decir: cocina, niños y arte? El problema puede ser enfocado de diversa forma, dependiendo de la postura que se adopte frente a él: ¿Cuál es el rol que ha jugado la mujer en la historia? o ¿cuál es el rol que le han permitido jugar? ¿Cuál es el papel que ella ha querido representar? ¿ ¿cuál es el papel que le han asignado?

Es decir, dependiendo de quién pregunte, el tono y el contenido de las interrogaciones tendrán una connotación diversa, positiva o negativa, burlona o lastimera. En cualquier caso, las preguntas no hacen otra cosa que poner en evidencia la necesidad de rever esta actitud humana de dividir, de discriminar, de pensar y actuar más en función de las diferencias antes que en las capacidades.

El gran pensador español, Ortega y Gasset decía que el ser humano es el resultado de la suma del Yo y sus circunstancias. El Yo como la manifestación de aquellas características que lo diferencian de otras criaturas y especies. Sus circunstancias, es decir aquellas manifestaciones vitales que rodean al ser humano, y ejercen sobre él, una poderosa influencia en la conformación de aquello que llamamos "personalidad". 
Es que la vida de todo ser humano está marcada por el espacio y la geografía en la que por suerte le toca vivir. Pero, esa geografía cambia al igual que los seres humanos que en ella habitan, en función del tiempo. Las épocas, las eras, los siglos, los años, modifican la naturaleza y modifican el comportamiento social de la especie humana, ya sea que se la considere como individuo o como parte integrante de una sociedad.

Lastimosamente, debemos reconocer, que la actitud discriminatoria contra la mujer, atraviesa casi todas las épocas, todos los siglos, y lo que es más grave, no ha sufrido modificaciones significativas. Aunque, justo es reconocerlo, que en las últimas décadas parecería que varios síntomas mueven al optimismo de que veremos cerca los tan anhelados cambios.

Por la vigencia del pensamiento y las palabras he querido recordar lo dicho por el filósofo alemán Friedrich Hegel: "los hombres comprenden el verdadero significado de su tiempo, solo poco a poco". Es que lo nuevo que nace en una sociedad y que determina su futuro, muy a menudo no se atisba con la claridad y la celeridad debida. Las fuerzas del ayer levantan barreras para defender estructuras, relaciones, costumbres e ideas, y de esta manera retrasa y obstaculiza el avance de la historia. El peor enemigo del progreso, dijo un pensador francés: "son los mitos que nos atan al pasado".

Históricamente, en América Latina, hemos venido construyendo eso que llamamos República e insistimos en la aplicación de un sistema político denominado Democracia. Sin embargo al haber partido de conceptos válidos pero mal entendidos, su aplicación ha sido equivocada.

La República como un territorio donde una sociedad ejerce su soberanía, ha sido mal interpretada y ha dado pie a un ejercicio del poder desde la perspectiva de grupos hegemónicos interesados en alcanzar sus intereses, los que, casi nunca han coincidido con el bien común.

El concepto de Democracia como una forma de interrelacionarse social y políticamente, ha sido distorsionado y se lo ha convertido en un escenario de discrímenes y divisiones excluyentes. 
Pero no se crea que esta descripción corresponde a años recientes. No, la descripción es una objetiva constatación de lo sucedido todos los años de vida republicana, que han estado signados por estos comportamientos.

Me pregunto: ¿será que no han cambiado las cosas por voluntad del pueblo? o será ¿que sus líderes y dirigentes no han tenido el coraje de plantear nuevos paradigmas? ¿Será que no existen otros caminos ni alternativas de entender un país? o, ¿será que al igual que el Conde Gatopardo preferimos cambiar algo para que todo siga igual?

Las respuestas a estas interrogantes, si somos sinceros, llevarán impregnadas parte de nuestra responsabilidad.

Es que debemos entender a nuestros países como una responsabilidad individual y colectiva. Individual en la medida que exigimos nuestros derecho básico a la vida, a la educación, a la salud, a un alimento, en suma, a alcanzar aquello que llamamos felicidad. Pero unido intrínsecamente a estas demandas viene nuestra responsabilidad de construir una solidaridad colectiva, un escenario donde sea posible alcanzar esos objetivos.

Partiendo de la constatación de estas divisiones y discrímenes podemos diseñar el mundo que queremos. En este intento no podemos descuidar, por un instante siquiera, el enfrentamiento entre dos posiciones al parecer irreconciliables que ahora dividen al mundo: la macro economía, la globalización del mercado, versus, la aplicación de políticas sociales solidarias. Esta lucha, en los últimos tiempos, ha cobrado una vigencia inusitada y no puede ser conocida, peor aceptada, desde las posiciones intransigentes imperantes hasta ahora, porque los resultados de esa lucha han traído como consecuencia un mayor dolor para una cada vez más creciente masa de seres humanos.

¿Cómo podemos conciliar esas dos opciones? ¿Cómo podemos fortalecer la presencia de la solidaridad en un mundo sin recursos? Pero, también, ¿cómo podremos fortalecerla en un mundo donde se predica y se practica la individualidad? 
Sobre estas posiciones, seguramente, seguiremos discutiendo durante mucho tiempo porque no existe una fórmula mágica que supere la infinidad de aristas que el tema plantea.

Sin embargo, no puedo dejar pasar la oportunidad de decir con claridad que estoy en contra de lo que sostiene la economía tradicional, de que todo aquello que se invierte directamente en el ser humano es un gasto y debe ser contabilizando como tal. Yo creo que eso no es así. Lo que se gasta en el ser humano es la mejor y la más rentable inversión, porque en poco tiempo esa cifra retorna en una sustancial mejora de la calidad de vida.

Pero, para aplicar este concepto económico hace falta reconceptualizar la forma de aplicar la Democracia.

De lo que se trata es de refundar un país, de un modo participativo, con el concurso de todos, porque si se trata de crear una nueva realidad social, entonces nadie puede desentenderse de esta tarea. Es obligación de todos el pensar en este nuevo paradigma. La democracia representativa que ahora practicamos debe transformarse en una democracia participativa que deje atrás toda forma de discrimen y de injusticia.

En este marco, en América Latina, y creo que en casi todos los continentes y regiones del mundo, la participación de la mujer en la vida política ha sido limitada. Contados son los casos en que la mujer ha incursionado en esta área, y, lastimosamente, no siempre el éxito les ha acompañado a sus afanes.

Es que quizás, por una formación o deformación propia de nuestro género, la mujer puede contribuir a los destinos de su país con la capacidad de la simultaneidad, que abarcando en su concepción varias áreas, puede integrarlas en la búsqueda de la solución de sus problemas. La mujer puede juntar lo económico con lo social, lo cultural con lo deportivo, su ternura con la fortaleza para tomar decisiones. Pero, sobre todo, la mujer puede y debe contribuir al saneamiento de la política con su comportamiento ético, lejos de los amarres de trastienda y de mezquinos intereses.

Los cambios sociales se construyen teniendo presentes las utopías. Ellas son las que mueven las voluntades y marcan la luz al 
final del camino. Si un ser humano no tiene sueños por alcanzar, no merece vivir el futuro. Por eso creo que debemos luchar por alcanzar nuestros sueños y hacernos merecedoras de vivir nuestras utopías.

Sin embargo, es importante que las mujeres y hombres que conformamos la sociedad, no nos detengamos en el mero análisis de la situación de la mujer. Debemos rescatar la importancia de esta temática, reconocer las diferencias entre hombres y mujeres, así como reconocer los valores de cada uno. Adicionalmente debemos considerar aspectos que al aplicarse efectivamente, permitan que la mujer y el hombre se enfrenten a la vida de manera equitativa, con las mismas oportunidades y en igualdad de condiciones y espacios.

En este proceso es de singular importancia considerar la incidencia de la mujer en el núcleo familiar. "...Los esposos, los padres, en general los hombres, deben tener mucha sensibilidad al cambio que está sufriendo la humanidad y nuestra actual civilización. La comprensión de este cambio es muy importante, entre el hombre y la mujer que forman la familia dentro de esta moderna estructura antropológica de la sociedad...". Sin esta comprensión, será difícil que la mujer pueda asumir el rol protagónico que se espera de ella en nuestras sociedades.

Debemos tener presente la importancia de la contribución de la mujer -que no excluye al hombre- a la vida social, política, económica y cultural, así como su función en la familia, especialmente en la educación de los hijos. La igualitaria participación de hombres y mujeres en todos los campos, es indispensable para el desarrollo total de un país, el bienestar del mundo y la causa de la paz. Por tanto, es necesario garantizar el reconocimiento universal, de hecho y de derecho, del principio de igualdad del hombre y la mujer, evitando todo acto discriminatorio, que menoscabe la dignidad humana.

"Estamos pasando por una transformación que modificará el sentido de la política y la economía en el siglo venidero. No existirán productos ni tecnologías nacionales, ni siquiera industrias nacionales. Ya no habrán economías nacionales, al menos tal como concebimos hoy la idea. Lo único que persistirá dentro de las fron- 
teras nacionales será la población que compone un país. Los bienes fundamentales de una nación serán la capacidad y destreza de sus ciudadanos. La principal misión política de una nación consistirá en manejarse con las fuerzas centrífugas de la economía mundial que romperán las ataduras que mantienen unidos a los ciudadanos."

A pesar de la verdad contenida en esta cita pronunciada por el ExMinistro norteamericano de Trabajo Robert B. Reich, está incompleta, pues no reconoce la infinidad de elementos nuevos que aparecen, día tras día, y cuya acción logra modificar el análisis y, por consiguiente, las conclusiones a las que se puede arribar.

Es que nuevos actores trabajan en distintos escenarios provocando el aparecimiento de desconocidas realidades. En la política, en la cultura, en lo social y en lo económico el mundo ha sufrido, sufre y sufrirá tantos cambios que, en ocasiones, resulta difícil entenderlo.

En lo político, la caída del muro de Berlín, modificó el mapa geopolítico y los referentes de la política mundial. Desde 1989, el mundo bipolar en el que crecimos, que basaba su existencia en una lucha de contrarios donde cada uno quería imponer su criterio sobre los demás, desapareció. Y por sorprendente que parezca, esa lucha producía un equilibrio de fuerzas que permitía la existencia de una precaria seguridad y paz mundial. Ahora, cuando existe el imperio de una sola fuerza política, vemos como se yergue el imperio de una sola ideología y la imposición de un único sistema de gobierno. Y los acontecimientos del 11 de septiembre del año 2001, marcan un cambio en esta concepción geopolítica que pone a pensar al mundo en el tratamiento de la diversidad.

Una rápida y superficial mirada a la economía mundial de finales del siglo XX, no permite mirar con optimismo la llegada de un día en que los seres humanos podamos, al menos, vivir con dignidad. Parecería que por el contrario, estemos a las puertas de un deterioro mayor de las condiciones en las que se desenvuelve la cuotidianidad. Los medios de comunicación han modificado el lenguaje de todos los seres humanos. 
Palabras, ideas y conceptos tales como: producto nacional bruto, balanza comercial, tasas de crecimiento, tasas de desempleo, productividad, valor de los activos, rentabilidad, eran hasta hace poco exclusivas de los círculos de iniciados en el mundo de la economía y las finanzas. Sin embargo, ahora, pertenecen a todos los círculos, y cada uno lo comprende de acuerdo con su particular punto de vista. La economía está en auge, un poco menos ahora con la recesión norteamericana todos hablan de ella, y sin embargo, cada conjunto de cifras y cálculos provoca inquietudes tales como: ¿Vamos mejor o peor que antes? ¿Qué pueden significar esos números para nuestro futuro económico?

Bajo toda esa discusión, permanece latente la idea de que todos los seres humanos estamos embarcados en una misma nave, y por lo tanto, sufrimos las mismas consecuencias por las mismas causas.

Sin embargo, esto no es así. La realidad que sufre cada segmento poblacional es diferente, lo mismo que su protagonismo. En las estadísticas mundiales aparecen representados más los hombres que las mujeres, los ricos más que los pobres, los blancos más que los mestizos, los educados y con un título más que los que no lo detentan. Bajo esta óptica podemos decir que existen unos seres que son considerados más humanos que otros. Seres de primera y seres de segunda y tercera categoría. Seres a los que la historia les otorga un protagonismo, mientras a otros les obliga a permanecer de espectadores del drama.

Lo peor de todo lo analizado es que lo micro, se reproduce en lo macro, por eso, las desigualdades entre los hombres son similares a la desigualdad entre las naciones. La brecha entre ricos y pobres es igual a la existente entre países pobres y países ricos, y no logra ser vencida a pesar de los esfuerzos que se emprenden. Más bien, día a día, parecería que asistimos al triunfo despiadado y cruel de aquel principio draconiano de la sobrevivencia del más fuerte y la muerte del más débil.

Por todo ello, no resulta sorprendente el que en el mundo de la macro-economía y de las finanzas internacionales, las cifras reve- 
len una visión unilateral y por lo tanto incompleta de la realidad en la que vivimos los seres humanos en los inicios de este siglo XXI. Si por un lado, uno de los indicadores crece en un determinado porcentaje, debemos aceptar que ese crecimiento se da a costa de la pauperización de otro sector, ¿qué y quién provoca ese crecimiento?, ¿qué segmento de la población es el beneficiado, y cuál sufre las consecuencias de ese desarrollo?

Como herencia de las ciencias físicas newtonianas, los seres humanos hemos arribado a una limitada visión que nos impide mirar simultáneamente todas las causas que inciden sobre un problema. La educación especializada, también logra reducir la capacidad de comprensión. Es aquí, precisamente, donde radica el espacio de la mujer. Aquí puede aportar de mejor manera a un cambio de la sociedad. La mujer, casi que por deformación histórica, en nuestras sociedades ha permanecido relegada a cumplir una inmensa cantidad de funciones al interior de su hogar. En esa condición radica su debilidad y su fuerza. En ese escenario hemos aprendido a desarrollar una cualidad no siempre reconocida, la simultaneidad. Nosotros podemos trabajar en varios campos, al mismo tiempo. Es que atender el hogar significa una variedad de problemas que deben ser resueltos al mismo tiempo, so pena de que su descuido signifique el agravamiento de las condiciones de vida al interior del hogar. Podemos reparar en un ejemplo común, en el que estuvimos o estamos inmersas: la madre de familia, simultáneamente, vigila la cocina, habla por teléfono, ayuda a sus hijos en las tareas escolares y hasta mira la televisión: todo ello al mismo tiempo y bien hecho.

Cada miembro de la familia trae consigo sus problemas, cada uno de ellos demanda su pronta solución y como todas sabemos, la madre es la encargada de receptarlos y de solucionarlos. En suma, las mujeres somos capaces de integrar simultáneamente todos los elementos de un conflicto. Quizás eso es lo que más falta le hace a la política.

Es que un problema económico, al incidir en el ser humano, está compuesto de factores psicológicos, vocacionales, sociales, religiosos, artísticos, disciplinarios, educativos y, también, económi- 
cos. No puede ni debe ser mirado únicamente como un problema somático, así como tampoco como una cuestión puramente material. Todos los factores se conjugan y entremezclan, y todos deben ser atendidos al mismo tiempo.

Hoy, que vivimos la época de una economía global, las recetas para combatir los males nos dicen que hay que reformar el Estado, reducir su tamaño, ampliar el espacio para la iniciativa privada, competir con calidad. La riqueza se mide por el valor agregado que un país es capaz de aportar. En suma, se busca la eficiencia y la eficacia. Pero, tras ello está presente la necesidad de una política social coherente y sostenida que aporte al aparecimiento de un nuevo ser humano, que desde su nacimiento tenga la oportunidad de alimento, salud y educación. Una política social que cuide el medio ambiente y propenda a un desarrollo sostenible.

En este contexto, debemos modificar el concepto mismo del Estado, y redefinir sus roles a fin de que pueda aparecer ese nuevo ser humano. Si pretendemos modificar la realidad, en su globalidad, entonces el aporte de la mujer en la concepción misma del Estado y de sus funciones, debe ser entendido como un desafío aceptado y emprendido por las mujeres. No podemos ni debemos quedamos al margen de las decisiones políticas que hoy en día configuran el mundo del mañana.

Ese desafío debe basarse en la simultaneidad, en la aplicación de una política integral e integradora, donde no prevalezca lo económico sobre los social, ni atienda únicamente lo social en desmedro de lo económico. Ambas áreas deben ser cobijadas por una preocupación constante del medio ambiente. Es decir que la integración de los conceptos y de las voluntades son las herramientas para alcanzar una mejora en la calidad de vida de los seres humanos.

No puedo dejar de mencionar, en este momento, a una enfermedad, que aparece como individual pero que conspira contra el tan anhelado desarrollo sostenible de una sociedad: me refiero a la corrupción. Un mal que amenaza con la destrucción de nuestros países, a la sobrevivencia misma de nuestras sociedades. Los va- 
Iores tradicionales de la honradez, de la verdad, de la justicia, han demostrado que son fundamentales en las relaciones sociales. Sin ellos, los pueblos no pueden desenvolverse. Sin su presencia cunde la desconfianza y las fuerzas sociales pierden su vigor.

Las estadísticas señalan que varios miles de millones de dólares se evaporan de las economías de nuestros países como producto de una corrupción rampante. La pérdida de valores éticos de los líderes afecta también la confianza de los pueblos en el sistema de gobierno. La democracia, entonces, no puede cumplir su cometido de dignificar a los pueblos y otorgarles una mejora permanente en sus niveles de vida.

Entonces, un aporte fundamental de quienes pretendemos ser líderes de nuestros pueblos, y por supuesto, de las mujeres, es el acercarse a la política y a la economía desde una dimensión ética que destruya a las fuerzas negativas de la sospecha y el desaliento y devuelva la esperanza a los pueblos. Para ello hace falta una sólida formación que construya nuevas condiciones en que la política aporte al desarrollo sostenible. Quizás otra forma de acercarse a la política sea la de conocer, sin miedo, los resortes en los que, actualmente, se desenvuelve, entre bastidores, la economía y los negocios, para luego procurar destruir los negativos y profundizar en los positivos o al menos, modificarlos para extender la cobertura de sus beneficios.

Cumplidas esas condiciones previas, entonces, debemos acordar con los organismos internacionales que, los índices con los que se debe medir el desarrollo de un país, no pueden estar ligados únicamente a cifras económicas, sino a los índices de la calidad de vida. Entre ellos, debemos mirar las cifras de analfabetismo, de escolaridad, de salubridad, de calidad profesional, a fin de mirar con optimismo los días por venir.

Estos hechos definen los límites de un nuevo campo para la oportuna acción del Estado, que permita integrar ciertos recursos del sector privado y los mecanismos del mercado, a fin de que los sectores marginados puedan financiar sus necesidades básicas. 
Los problemas de pobreza, desigualdad y marginación pueden enfrentarse, con eficacia, creando nuevas y fructíferas alianzas entre el Estado, la empresa privada y la sociedad civil, a través de la creación de nuevas instituciones como fondos de inversión y redes de seguridad social. Todo ello en un marco de respeto al ser humano y al entorno natural en el que vive.

Por ello, se hace indispensable pensar. O tal vez al menos imaginar, algunas ideas respecto a estos nuevos liderazgos, que por supuesto se aplican a la política, pero que también aparecen como válidos en el mundo empresarial, en el académico y en otros.

Sabemos que una estrategia importante para el líder es la comunicación. Se dice que lo no comunicado es como lo no hecho, y tenemos que concluir que esto es verdad. "Sin una comunicación creíble y abundante, jamás se capturará el corazón y la mente de la gente", dice Kotter, y, "la comunicación se da tanto en las palabras como en los hechos". "Nada socava el cambio como un comportamiento inconsistente con la comunicación verbal por parte de los individuos importantes".

Estas frases realmente no requieren mayor comentario, a no ser el destacar la veracidad de lo manifestado, pues comunicación -que no debemos confundir con publicidad-si bien es vital para hacer conocer propuestas, difundir ideales, etc., si no va acompañada de acciones, y sobre todo de coherencia entre el dicho y el hecho, va dramáticamente al fracaso, a la defraudación.

Otro aspecto importante para los líderes del cambio, es recordarles aquello de que: "Los obstáculos se encuentran generalmente solo en la mente de la gente, y el desafío consiste en convencerles de que no existen barreras externas".

También tenemos que estar conscientes de que las tareas que realmente valen la pena, no son tan sencillas y que no debemos confundir las metas y los logros parciales, con los más amplios y hasta definitivos. "El cantar victoria demasiado pronto es como tropezarse y caer en un agujero de desagüe en el camino hacia el cambio significativo". Las palabras pueden parecer demasiado duras, pero son bastante demostrativas. En países como el 
Ecuador, debemos estar también conscientes de que uno de los retos que debemos ponernos es superar las condiciones de desigualdad, dar esa lucha recurrente contra la pobreza. El premio Nobel de Economía de 1979, Theodore W. Schultz decía: "Para describir la pobreza, el idioma es más rico que la teoría" por eso no vamos a dedicamos a describirla, está allí, está aquí.

Pero, volviendo sobre el cambio, del que siempre se habla, ya el filósofo griego Heráclito lo decía, quinientos años antes de Cristo, al referirse a que nadie puede bañarse dos veces en las mismas aguas de un río, por lo que debemos convenir plenamente con Yehexkel Dror cuando nos afirma: "El proceso de cambio que vivimos impone serios desafíos a la capacidad de gobernar" y ello no debe hacemos caer en subterfugios tales como el uso del término ingobernabilidad, que "es con frecuencia incorrecto y peligroso. Es incorrecto porque lo que se entiende por ingobernabilidad de la sociedad, suele ser el resultado del fracaso de los gobiernos por ajustarse a las cambiantes condiciones. $Y$ es peligroso porque proporciona una coartada para las torpezas del gobierno, que a su vez echará la culpa a la sociedad".

Como puede observarse, las reflexiones se encausan por diferentes caminos. Yo he preferido enfocar el tema, mediante la confluencia de palabras liderazgo, estadista, cambio... podría añadir mucho más, tal vez la palabra bienestar, como un deber ser, como una búsqueda en medio de las tormentosas aguas en las que nos desenvolvemos, y hasta podría usar, para terminar, aquella que nos aflora a la punta de la lengua o se refugia en los intersticios de nuestros pensamientos: felicidad, anhelo supremo, ambición máxima , sí, tal vez, pero inevitablemente presente en nuestros sueños, en nuestra búsqueda de amor, de momentos fugaces que hasta aspiraríamos que fueran eternos. 
126 